\title{
Role of serum FSH for predicting success of sperm retrieval for patients undergoing microdissection-TESE: a retrospective analysis
}

\author{
B. Kalpana, Soumya Ranjan Panda*
}

Department of Reproductive Medicine, Guru Hospital, Madurai, Tamil Nadu, India

Received: 29 August 2018

Accepted: 27 September 2018

\section{*Correspondence:}

Dr. Soumya Ranjan Panda,

E-mail: drsome4141@gmail.com

Copyright: (C) the author(s), publisher and licensee Medip Academy. This is an open-access article distributed under the terms of the Creative Commons Attribution Non-Commercial License, which permits unrestricted non-commercial use, distribution, and reproduction in any medium, provided the original work is properly cited.

\begin{abstract}
Background: The method of sperm retrieval for azoospermic patients had evolved in the recent times and microdissection TESE being the latest method for the same. Patient selection for TESE has always been an area of concern. Although low level of serum FSH is good indicator for successful sperm retrieval for conventional TESE, its role for micro-TESE is debatable. The primary objective of present study is to determine whether serum FSH level can predict success rate of sperm retrieval by micro-dissection TESE (micro-TESE). In addition, authors have compared the outcome of ICSI-TESE cycles between obstructive and nonobstructive azoospermia.

Methods: This is a retrospective study conducted at Guru Hospital, Madurai, India between January 2014 and February 2018. Data collected from the previous hospital records.

Results: Out of a total 147 azoospermic patients included in present study $68(46.3 \%)$ were obstructive azoospermic whereas $79(53.7 \%)$ were of nonobstructive variety. While assessing TESE- ICSI outcomes among obstructive versus nonobstructive azoospermic groups, authors found that the two groups had similar clinical pregnancy rates per transfer, chemical pregnancy rates per transfer, implantation rates, live birth rates and abortion rates per transfer. Authors also compared serum FSH level between micro TESE positive and micro-TESE negative groups. But there was no significant difference between the two groups. Authors could not find any definite correlation between serum FSH and sperm retrieval rate.

Conclusions: For nonobstructive azoospermic men, TESE-ICSI provides a hope to parenting their genetically own child. Of course, before advising TESE-ICSI, nonobstructive azoospermic men should be counseled regarding the low success rate of sperm retrieval. Serum FSH level cannot predict success rate of sperm retrieval for patients undergoing micro-TESE.
\end{abstract}

Keywords: Azoospermia, FSH, ICSI, Micro-TESE

\section{INTRODUCTION}

Azoospermia is the most severe form of male infertility. ${ }^{1}$ ICSI with surgically retrieved testicular sperm has revolutionized the management of azoospermic males and represents a hope even for nonobstructive azoospermic males to parent their own genetic child. Testicular sperm extraction (TESE) remains the oldest and most informative diagnostic modality to differentiate between men with obstructive and nonobstructive azoospermia. $^{2,3}$ The method of sperm retrieval had evolved in the recent times and micro-dissection TESE being the latest method for the same. Although serum FSH can predict success rate of conventional TESE, research is going on whether this fact holds true for micro-dissection TESE also. Less is known about the efficacy and outcome of TESE-ICSI performed with spermatozoa from men with nonobstructive azoospermia. 


\section{METHODS}

This is a retrospective study conducted at Guru Hospital, Madurai, India involving 133 azoospermic patients having their first testicular biopsy between January 2013 and February 2018. Data collected from the previous hospital records.

\section{Inclusion criteria}

All azoospermic patients in whom a TESE procedure was conducted for sperm retrieval were included for the study.

\section{Exclusion criteria}

Patients who had a history of TESE in the past were excluded.

All patients were diagnosed with azoospermia, based on the complete absence of spermatozoa in the ejaculate in at least two semen samples. All patients in the group underwent andrological investigation suitable for azoospermic patients. This included physical examination and patients' history-taking along with evaluation of their hormonal profile, peripheral blood karyotype and transrectal ultrasound. Diagnosis of nonobstructive azoospermia was based upon a histological report, taken during the current procedure.

All the nonobstructive azoospermic patients underwent micro-TESE procedure for sperm retrieval whereas obstructive azoospermic patients underwent testicular sperm aspiration at first followed by conventional TESE/ micro-TESE if sperm were not retrieved during aspiration.

All micro-TESE procedures were performed by the same urologist with expertise in microsurgery. Procedures were performed under spinal anaesthesia, with the patient positioned on the operating table in a supine position. Microdissection was performed using a floor-standing operating microscope to expose the seminiferous tubules. Areas with dilated tubules were identified, from which multiple sections of testicular tissue were obtained. These specimens were analysed for the presence of sperm after teasing all of the tubules. Any viable sperm was collected and prepared for use in ICSI. A specimen was taken for histological analysis during the same surgical procedure.

In couples for whom testicular sperm were retrieved and frozen, or in couples undergoing a combined TESE-ICSI procedure, female partners underwent ovarian stimulation using urinary or recombinant FSH in combination with GnRH (gonadotrophin releasing hormone) agonist or antagonist.

Fertilization rates were expressed as the percentage of oocytes with two distinct pronuclei per injected metaphase II oocytes. Embryos were classified according to their morphological appearance. Normally cleaving embryos with $50 \%$ fragmentation were considered eligible for transfer. Up to three embryos (exceptionally four) were transferred into the uterine cavity on day 3 or 5 after injection.

Pregnancy was diagnosed by elevated serum hCG levels on at least two consecutive occasions. A clinical pregnancy was defined by the presence of a gestational sac at transvaginal ultrasound 5 weeks after embryo transfer. Patients with an unknown outcome were considered not pregnant. The implantation rate was calculated as the number of gestational sacs with fetal heartbeat divided by the number of embryos transferred. Fertilisation rate, implantation rate, clinical pregnancy rate, abortion rate, chemical pregnancy rate and live birth rate were calculated as outcome measures. Authors compared the serum FSH level of nonobstructive azoospermic men between those who are micro-TESE positive and those with negative result.

\section{Statistical analysis}

All statistical analysis was performed using statistical software SPSS version 20. A P-value of 0.05 or less was considered as statistically significant.

\section{RESULTS}

Out of a total 147 azoospermic patients included in present study $68(46.3 \%)$ were obstructive azoospermic whereas $79(53.7 \%)$ were of nonobstructive variety (Table 1).

Table 1: Percentage of obstructive and nonobstructive azoospermic patients with sperm retrieval rate.

\begin{tabular}{|lll|}
\hline & $\begin{array}{l}\text { No. of } \\
\text { patients }\end{array}$ & $\begin{array}{l}\text { Sperm } \\
\text { retrieval rate }\end{array}$ \\
\hline $\begin{array}{l}\text { Obstructive } \\
\text { azoospermia }\end{array}$ & $68(46.3 \%)$ & $68(100 \%)$ \\
\hline $\begin{array}{l}\text { Nonobstructive } \\
\text { azoospermia }\end{array}$ & $79(53.7 \%)$ & $44(55.69 \%)$ \\
\hline Total & 147 & $112(76.19 \%)$ \\
\hline
\end{tabular}

Table 2 depicts various demographic parameters of the two groups. Age distribution of both these groups were similar (32.51 \pm 3.98 versus $33.17 \pm 4.19$; p-value: 0.3314$)$. Similarly, there was no significant difference between BMI $(29.49 \pm 1.40$ versus 29.42 \pm 2.78 ; p-value: 0.8511$)$ and duration of infertility $(6 \pm 2.86$ versus $6.84 \pm 3.77$; pvalue: 0.1352 ) among these two groups. The TESA positivity rate was $68 / 68(100 \%)$ versus $44 / 79(55.69 \%)$ among obstructive and nonobstructive azoospermic groups respectively which was found to be statistically significant difference (p-value: 0.0001). Other baseline characteristics like number of oocytes retrieved $(7.23 \pm 1.41$ versus $7.59 \pm 1.64$; p-value: 0.1592$)$ and number of embryos transferred $(2.86 \pm 0.53$ versus 
2.96 \pm 0.54 ; p-value: 0.2607 ) were also similar while comparing between TESE positive obstructive and TESE positive nonobstructive azoospermic groups. While assessing outcomes, authors found that the two groups had similar clinical pregnancy rates per transfer $51.47 \%$ versus 47.72\%; p-value: 0.8467), chemical pregnancy rates per transfer $(4.41 \%$ versus $2.27 \%$; P-value: 1.0000$)$, implantation rates $(31.79 \%$ versus $27.4 \%$; P-value: $0.4533)$, live birth rates $(44.11 \%$ versus $43.18 \%$; P-value: $1.000)$ and abortion rates per transfer $(2.94 \%$ versus 2.27\% P-value: 1.0000) (Table 3). The rate of sperm retrieval associated with various testicular histological pattern observed among micro-TESE positive vs microTESE negative nonobstructive azoospermic patients are $35 \%$ versus $65 \%$ (Sertoli cell only syndrome), $45.45 \%$ versus $54.55 \%$ (maturation arrest), 80.64\%, $19.36 \%$ (hypospermatogenesis) and 33.33 versus $66.67 \%$ (atrophic hyalinization) (Table 4).

Table 2: Demographic profile and TESE positive rate of azoospermic patients.

\begin{tabular}{|llll|}
\hline & $\begin{array}{l}\text { Obstructive } \\
\text { azoospermia } \\
(\mathrm{n}=68)\end{array}$ & $\begin{array}{l}\text { Nonobstructive } \\
\text { azoospermia } \\
(\mathrm{n}=79)\end{array}$ & p-value \\
\hline Age & $32.51 \pm 3.98$ & $33.17 \pm 4.19$ & 0.3314 \\
\hline BMI & $29.49 \pm 1.40$ & $29.42 \pm 2.78$ & 0.8511 \\
\hline $\begin{array}{l}\text { Duration of } \\
\text { infertility }\end{array}$ & $6 \pm 2.86$ & $6.84 \pm 3.77$ & 0.1352 \\
\hline $\begin{array}{l}\text { TESE } \\
\text { positive rate }\end{array}$ & $68 / 68(100 \%)$ & $44 / 79(55.69 \%)$ & 0.0001 \\
\hline
\end{tabular}

Table 3: Baseline characteristics and outcome measures of ICSI-TESE cycles.

\begin{tabular}{|c|c|c|c|}
\hline & $\begin{array}{l}\text { Sperm retrieval positive } \\
\text { Obstructive azoospermia ( } n=68 \text { ) }\end{array}$ & $\begin{array}{l}\text { Sperm retrieval positive Non- } \\
\text { obstructive azoospermia }(n=44)\end{array}$ & P-value \\
\hline \multicolumn{4}{|l|}{ Baseline characteristics } \\
\hline Oocytes (mean $\pm \mathrm{SD})$ & $7.23 \pm 1.41$ & $7.59 \pm 1.64$ & 0.1592 \\
\hline No. of embryos transferred (mean \pm SD) & $2.86 \pm 0.53$ & $2.96 \pm 0.54$ & 0.2607 \\
\hline \multicolumn{4}{|l|}{ Outcome measures } \\
\hline Implantation rate & $62 / 195(31.79 \%)$ & $34 / 124(27.4 \%)$ & 0.4533 \\
\hline Clinical Pregnancy rate per transfer & $35 / 68(51.47 \%)$ & $21 / 44(47.72 \%)$ & 0.8467 \\
\hline Livebirth rate & $30 / 68(44.11 \%)$ & $19 / 44(43.18 \%)$ & 1.0000 \\
\hline Abortion rate per transfer & $2 / 68(2.94 \%)$ & $1 / 44(2.27 \%)$ & 1.0000 \\
\hline Chemical pregnancy rate per transfer & $3 / 68(4.41 \%)$ & $1 / 44(2.27 \%)$ & 1.0000 \\
\hline
\end{tabular}

While authors compared the mean serum FSH level between micro-TESE positive vs micro-TESE negative nonobstructive azoospermic patients, authors found out that there is no statistically significant difference between the two groups. $(25.77 \pm 13.86$ versus $22.06 \pm 10.78$; Pvalue 0.1846 ). Also, the mean serum FSH level showed no difference while compared according to the testicular histological pattern between the two groups (Table 5).

To find whether there exists a correlation between serum FSH and sperm retrieval rate authors divided the nonobstructive azoospermic patients into four groups according to various range of serum FSH level (group-1 with serum FSH level $\leq 15$, group-2 with $15.1-30$, group-
3 with 30.1-45 and group-4 having serum FSH level $\geq 45.1$ ).

Table 4: Histology in nonobstructive azoospermic patients.

\begin{tabular}{|lll|}
\hline Pattern of histology & $\begin{array}{l}\text { Micro-TESE } \\
\text { positive }\end{array}$ & $\begin{array}{l}\text { Micro-TESE } \\
\text { negative }\end{array}$ \\
\hline $\begin{array}{l}\text { Sertoli cell only } \\
\text { syndrome }\end{array}$ & $7 / 20(35 \%)$ & $13 / 20(65 \%)$ \\
\hline Maturation arrest & $10 / 22(45.45 \%)$ & $12 / 22(54.55 \%)$ \\
\hline Hypospermatogenesis & $25 / 31(80.64 \%)$ & $6 / 31(19.36 \%)$ \\
\hline Atrophic hyalinisation & $2 / 6(33.33 \%)$ & $4 / 6(66.67 \%)$ \\
\hline Total & $44 / 79(55.69 \%)$ & $35 / 79(44.31 \%)$ \\
\hline
\end{tabular}

Table 5: Serum FSH level according to testicular histology pattern among nonobstructive azoospermic cases.

\begin{tabular}{|llll|}
\hline Pattern of histology & Serum FSH level among nonobstructive aroospermic cases & P-value \\
\hline Sertoli cell only syndrome & Micro-TESE positive (mean \pm SD) & Micro-TESE negative (mean \pm SD) & 0.8209 \\
\hline Maturation arrest & $27.71 \pm 13.54$ & $29.30 \pm 15.34$ & 0.9156 \\
\hline Hypospermatogenesis & $22.7 \pm 11.07$ & $23.25 \pm 12.66$ & 0.5660 \\
\hline Atrophic hyalinisation & $25 \pm 3$ & $22.67 \pm 14.86$ & 0.7303 \\
\hline Total & $22.06 \pm 10.78$ & $27 \pm 7$ & 0.1846 \\
\hline
\end{tabular}


Table 6: Correlation of serum FSH level with sperm retrieval rate.

\begin{tabular}{|c|c|c|c|}
\hline $\begin{array}{l}\text { Groups according to range } \\
\text { of serum FSH }(\mathrm{mIU} / \mathrm{ml})\end{array}$ & Mean serum FSH (mIU/ml) & Sperm retrieval rate & \multirow{5}{*}{$\begin{array}{l}\text { Correlation coefficient } \\
\text { (r) between mean serum } \\
\text { FSH and sperm } \\
\text { retrieval rate is } 0.27 \text {. }\end{array}$} \\
\hline Group-1 $(\leq 15)$ & 11.39 & $12 / 23(52.17 \%)$ & \\
\hline Group-2 (15.1-30) & 21.92 & $22 / 38(57.8 \%)$ & \\
\hline Group-3 (30.1-45) & 34.85 & $4 / 7(57.14 \%)$ & \\
\hline Group-4 ( $\geq 45.1)$ & 48.18 & $6 / 11(54.54 \%)$ & \\
\hline
\end{tabular}

Then authors derived the correlation coefficient (r) between mean FSH level and sperm retrieval rate for each group. Correlation coefficient (r) was found out to be 0.27 which indicates that there is very weak correlation between serum FSH and sperm retrieval rate (Table 6).

\section{DISCUSSION}

Management of azoospermic males remains a challenge for IVF specialists. Spermatozoa from these men can be extracted by various technique and subsequently be used to fertilize the oocytes of their female partners by means of intracytoplasmic sperm injection (ICSI) giving these couple a chance of becoming biological parent., ${ }^{4,5}$ Azoospermia can be either obstructive or nonobstructive. The most common etiologies of obstructive azoospermia are congenital bilateral absence of the vas deferens (CBVAD), or by vasectomy or postinfectious epididymal obstruction. Nonobstructive azoospermia is due to a severe spermatogenic defect whereby there is not enough quantity of sperm production to 'spill over' into the ejaculate. Genetic mutations, chromosomal aberrations, cryptorchidism, chemotherapy or mumps orchitis, or idiopathic etiologies are the common cause of nonobstructive azoospermia.

Sperm retrieval rates reported of late in the literature were inconsistent. $^{6-9}$ According to Dabaja and Schlegel et al TESE-ICSI cycle has an aggregate chance of $25 \%$ of resulting in a live birth: spermatozoa are successfully retrieved in $50 \%$ of men with nonobstructive azoospermia and the subsequent use of these spermatozoa in one or more ICSI treatments results in a live birth rate of $50 \% .{ }^{9}$ In present study authors found a sperm retrieval rate of $47.69 \%$ in nonobstructive azoospermia where as $92.64 \%$ in the obstructive azoospermia group. This difference was found to be statistically significant ( $p$ value: 0.0204$)$.

There is a growing concern regarding the quality of spermatozoa in terms of DNA damage or maturation when collected from testicular semen of azoospermic patients. Regarding the outcome of ICSI in these nonobstructive azoospermia couples, generally there are conflicting views from different authors. Some authors reported a lower success rate when compared with couples with men showing normal spermatogenesis (obstructive azoospermia) or hypospermatogenesis while others found that the two groups were having similar clinical outcome following TESE-ICSI cycles. ${ }^{10,11}$

According to various literatures related to outcome of TESE-ICSI cycles in nonobstructive azoospermia, fertilization rate, has been reported as 38.6-68\%, implantation rate as $11.3 \%$, clinical pregnancy rate as 21 $46 \%$ and live birth rate as $20-43 \% .^{9,12-14}$ Tsai YR et al found a fertilisation rate of $90.4 \%$ versus $92.1 \%$, implantation rate of $27.2 \%$ versus $20.2 \%$, clinical pregnancy rate of $47.1 \%$ versus $45.6 \%$, live birth rate (per transfer) of $38.1 \%$ versus $32.9 \%$ for obstructive and nonobstructive azoospermic group respectively. ${ }^{11}$ Like present study Tsai YR et al also did not find any statistically significant difference between any of the outcome measures. ${ }^{11}$

In present study authors found a comparable outcome measures like clinical pregnancy rates per transfer (52.38\% versus $45.16 \%$; P-value: 0.8482$)$, chemical pregnancy rates per transfer $(4.76 \%$ versus $3.2 \%$; $\mathrm{P}$ value: 1.0000), implantation rates $(34.44 \%$ versus 28.26\%; P - value: 0.5145 ), live birth rates (44.44 versus 38.7; P- value: 0.8407) and abortion rates per transfer (3.17\% versus $3.2 \%$;P- value: 1.0000$)$ of TESA-ICSI cycles performed for obstructive or nonobstructive azoospermia. Zygote distribution, fertilization conditions, and pregnancy outcomes were comparable, as were the number of top-quality embryos transferred. Authors believe a well-trained embryologist plays a vital role in selecting a morphologically good quality sperm that contributes for best ICSI outcomes. This is because of the fact that a limited number of spermatozoa are retrieved and injected per treatment cycle for these patients. In contrast to previous literatures present study along with some other studies in recent literature are in support of the fact that after successful sperm extraction, outcome of ICSI cycles do not differ much between obstructive and nonobstructive azoospermic patients. Of course, choice of a good quality sperm is the key factor in this regard.

In present study authors could not find any definite correlation between serum FSH level and success rate of sperm retrieval. This could be due to the fact that serum FSH reflects an indirect measure of the predominant picture of spermatogenesis. On the other hand, microscopic dissection TESE (micro-TESE) is based on the principle that identifies the most advanced pattern and not necessarily the predominant pattern of 
spermatogenesis. Therefore, while FSH might predict the presence of sperm at random biopsy using conventional TESE techniques, this fact is not true for micro-TESE. ${ }^{15-}$ 18 Thus, micro-TESE has been shown to be more successful in sperm retrieval than a single biopsy or multiple random biopsies. ${ }^{19,20}$ Like present study Ramasamy et al also found similar results that serum FSH level does not have a definite correlation with sperm retrieval as far as the method of sperm retrieval is microTESE. ${ }^{21}$

\section{CONCLUSION}

In conclusion, albeit the fact that the sperm retrieval rate in nonobstructive azoospermic men is quite lower than their obstructive counterpart, the clinical outcome following TESE-ICSI is quite similar in both groups. This fact provides a hope for NOA men to parent their genetically own child. Of course, before advising TESEICSI, NOA men should be counselled regarding the success rate of sperm retrieval. A role of good embryologist cannot be under rated in this aspect. microscopic dissection TESE (micro-TESE) identifies the most advanced pattern of spermatogenesis and has shown to be more successful in sperm retrieval than a single biopsy or multiple random biopsies. Serum FSH level does not bear a definite correlation with success rate of sperm retrieval for patients undergoing micro-TESE. So, it's clinically inappropriate to exclude patients based on serum FSH level alone (even if FSH is $>45 \mathrm{IU} / \mathrm{ml}$ ).

Funding: No funding sources

Conflict of interest: None declared

Ethical approval: Not required

\section{REFERENCES}

1. Agarwal A, Mulgund A, Hamada A, Chyatte MR. A unique view on male infertility around the globe. Reprod Biol Endocrinol. 2015;13:37.

2. Nunez-Calonge R, Cortes S, Gago M, Lopez P, Caballero-Peregrin P. Increased fertilization rates after in vitro culture of frozen-thawed testicular immotile sperm in nonobstructive azoospermic patients. ISRN Urol. 2012:108576.

3. Tsai CC, Huang FJ, Wang LJ, Lin YJ, Kung FT, Hsieh $\mathrm{CH}$, et al. Clinical outcomes and development of children born after intracytoplasmic sperm injection (ICSI) using extracted testicular sperm or ejaculated extreme severe oligoasthenoteratozoospermia sperm: a comparative study. Fertil Steril. 2011;96:567-71.

4. Beharka R, Pacik D, Crha I. Long-term experience with MESA, TESE techniques in the University Hospital (FN) in Brno. Rozhl Chir. 2006;85:526-9.

5. Diemer T, Hauptmann A, WeidnerW. Treatment of azoospermia: surgical sperm retrieval (MESA, TESE, micro-TESE). Urologe. 2011;50:38-46.

6. Donoso P, Tournaye H, Devroey P. Which is the best sperm retrieval technique for non-obstructive azoospermia? A systematic review. Hum Reprod Update. 2007;13:539-49.

7. Ishikawa T. Surgical recovery of sperm in nonobstructive azoospermia. Asian J Androl. 2012;14:109-15.

8. Esteves SC, Miyaoka R, Orosz JE, Agarwal A. An update on spermretrieval techniques for azoospermic males. Clinics (Sao Paulo). 2013;68(Suppl 1):99110.

9. Dabaja AA, Schlegel PN. Microdissection testicular sperm extraction: an update. Asian J Androl. 2013;15:35-9.

10. Esteves SC, Agarwal A. Reproductive outcomes, including neonatal data, following sperm injection in men with obstructive and nonobstructive azoospermia: case series and systematic review. Clinics (Sao Paulo). 2013;68(Suppl 1):141-50.

11. Tsai YR, Huang FJ, Lin PY, Kung FT, Lin YJ, Lan KC. Clinical outcomes and development of children born to couples with obstructive and nonobstructive azoospermia undergoing testicular sperm extractionintracytoplasmic sperm injection: A comparative study. Taiwan J Obstet Gynecol. 2015;54(2):155-9.

12. Haimov-Kochman R, Prus D, Farchat M, Bdolah Y, Hurwitz A. Reproductive outcome of men with azoospermia due to cryptorchidism using assisted techniques. Int J Androl. 2010;33(1):e139-43.

13. Fadini R, Colpi E, Mignini Renzini M, Coticchio G, Comi R, Mastrolilli M, et al. Outcome of cycles of oocyte in vitro maturation requiring testicular sperm extraction for nonobstructive azoospermia. Fertil Steril. 2011;96(2):321-3.

14. Bromage SJ, Falconer DA, Lieberman BA, Sangar V, Payne SR. Sperm retrieval rates in subgroups of primary azoospermic males. Eur Urol. 2007;51(2):534-9.

15. Chen CS, Chu SH, Lai YM, Wang ML, Chan PR. Reconsideration of testicular biopsy and folliclestimulating hormone measurement in the era of intracytoplasmic sperm injection for nonobstructive azoospermia? Hum Reprod. 1996;11:2176-9.

16. Ezeh UI, Taub NA, Moore HD, Cooke ID. Establishment of predictive variables associated with testicular sperm retrieval in men with nonobstructive azoospermia. Hum Reprod. 1999;14:1005-12.

17. Jezek D, Knuth UA, Schulze W. Successful testicular sperm extraction (TESE) in spite of high serum follicle stimulating hormone and azoospermia: correlation between testicular morphology, TESE results, semen analysis and serum hormone values in 103 infertile men. Hum Reprod. 1998;13:1230-4.

18. Kahraman S, Ozgur S, Alatas C, Aksoy S, Balaban B, Evrenkaya $\mathrm{T}$, et al. High implantation and pregnancy rates with testicular sperm extraction and intracytoplasmic sperm injection in obstructive and nonobstructive azoospermia. Hum Reprod. 1996;11:673-6.

19. Okada H, Dobashi M, Yamazaki T, Hara I, Fujisawa $\mathrm{M}$, Arakawa $\mathrm{S}$, et al. Conventional versus microdissection testicular sperm extraction for 
nonobstructive azoospermia. J Urol. 2002;168:10637.

20. Tsujimura A, Matsumiya K, Miyagawa Y, Tohda A, Miura H, Nishimura K, et al. Conventional multiple or microdissection testicular sperm extraction: a comparative study. Hum Reprod. 2002;17:2924-9.

21. Ramasamy R, Lin K, Gosden LV, Rosenwaks Z, Palermo GD, Schlegel PN. High serum FSH levels in men with nonobstructive azoospermia does not affect success of microdissection testicular sperm extraction. Fertil Steril. 2009;92(2):590-3.

Cite this article as: Kalpana B, Panda SR. Role of serum FSH for predicting success of sperm retrieval for patients undergoing microdissection-TESE: a retrospective analysis. Int $\mathrm{J}$ Reprod Contracept Obstet Gynecol 2018;7:4609-14. 